\title{
Successful Endovascular Management of Intra-meatal Anterior Inferior Cerebellar Artery-Posterior Inferior Cerebellar Artery Variant Aneurysm
}

\author{
Vikram Bohra ${ }^{1}$ Romnesh DeSouza' ${ }^{1}$ Vikram Huded ${ }^{1}$ \\ ${ }^{1}$ Department of Neurology, NH Institute of Neurosciences, NH \\ Health City, Bangalore, Karnataka, India

\begin{abstract}
Address for correspondence Vikram Huded, DM, FINR, Head Interventional Neurology and Stroke, NH Institute of Neurosciences, NH Health City, 258/A, Bommassandra Industrial Area, Hosur road, Bangalore, Karnataka, India-560099

(e-mail: drvikramhuded@gmail.com).
\end{abstract}

\begin{abstract}
Anterior inferior cerebellar artery-posterior inferior cerebellar artery (AICA-PICA) variant or common trunk is seen frequently in vertebral angiograms as PICA is found to be hypoplastic or absent in approximately 20 to $25 \%$ of patients. There have been very few case reports of aneurysm arising in AICA-PICA variant. Intrameatal AICA aneurysms are also rare, with no reports involving AICA-PICA variant till date. Neurosurgical approach and clipping have been proposed as first-line treatment option for intrameatal AICA aneurysms. The authors report a case of a young woman presenting with subarachnoid hemorrhage, found to have a right AICA-PICA variant aneurysm in intrameatal location. The patient underwent coiling with parent vessel occlusion after an unsuccessful attempt at surgical management of the same. She recovered without

Keywords

- AICA-PICA variant

- intrameatal aneurysm

- coiling any postprocedure complication. This case report highlights the fact that endovascular approach can be used to manage distal AICA/AICA-PICA variant or intrameatal aneurysm with added advantage of avoiding the postprocedure complications associated with surgical management of the same.
\end{abstract}

A 45-year-old woman presented with history of suddenonset headache, recurrent vomiting, and mild imbalance on walking. There were no seizures, loss of consciousness, hearing impairment, tinnitus, facial weakness, neck manipulation, or head injury. On examination, the patient had tandem gait impairment. Subarachnoid hemorrhage (SAH) was seen on computed tomographic scan (CT) following which a digital subtraction angiogram (DSA), performed in other institute, revealed right anterior inferior cerebellar artery-posterior inferior cerebellar artery (AICA-PICA) variant with distal aneurysm (-Fig. 1A). Normal configuration of AICA and PICA was seen on left with no evidence of any arteriovenous malformation or fistula distal to AICA-PICA common trunk. The patient was posted for surgery, with plan for occipital to AICA-PICA variant bypass, but aneurysm could not be located during exploration of the vessel. Repeat DSA with three-dimensional (3D) angiogram overlapped with Xper CT confirmed an aneurysm in intrameatal location of right AICA-PICA common trunk (-Figs. 1B and C, and 2). Post exploration, the patient's headache worsened and developed intention tremors in the upper limb. Magnetic resonance imaging (MRI) showed edema with few lacunar infarcts in the right cerebellar hemisphere (-Fig. 1D, E). The patient was now taken up for coiling with parent vessel occlusion. With $6 \mathrm{~F}$ right femoral arterial access, a 6F Chaperone guiding catheter was negotiated into the left vertebral artery (VA). Echelon microcatheter over microwire was negotiated into the aneurysm, and after confirming location with microcatheter shoot, inside out coiling was done with multiple detachable platinum coils. Postcoiling angiogram showed exclusion of aneurysm from circulation and filling of the distal territory through collaterals (-Fig. 1F, G). The patient had an uneventful recovery and was discharged 1 week later with mild residual intention tremor. At 3-month follow-up, the patient had no residual deficit. received

June 6, 2017

accepted after revision

January 9, 2018
DOI https://doi.org/

10.1055/s-0038-1642107.

ISSN 2457-0214.
Copyright $\odot 2018$ by Indian Society of Vascular and Interventional Radiology
License terms

() (1) $\Theta \circledast$ 

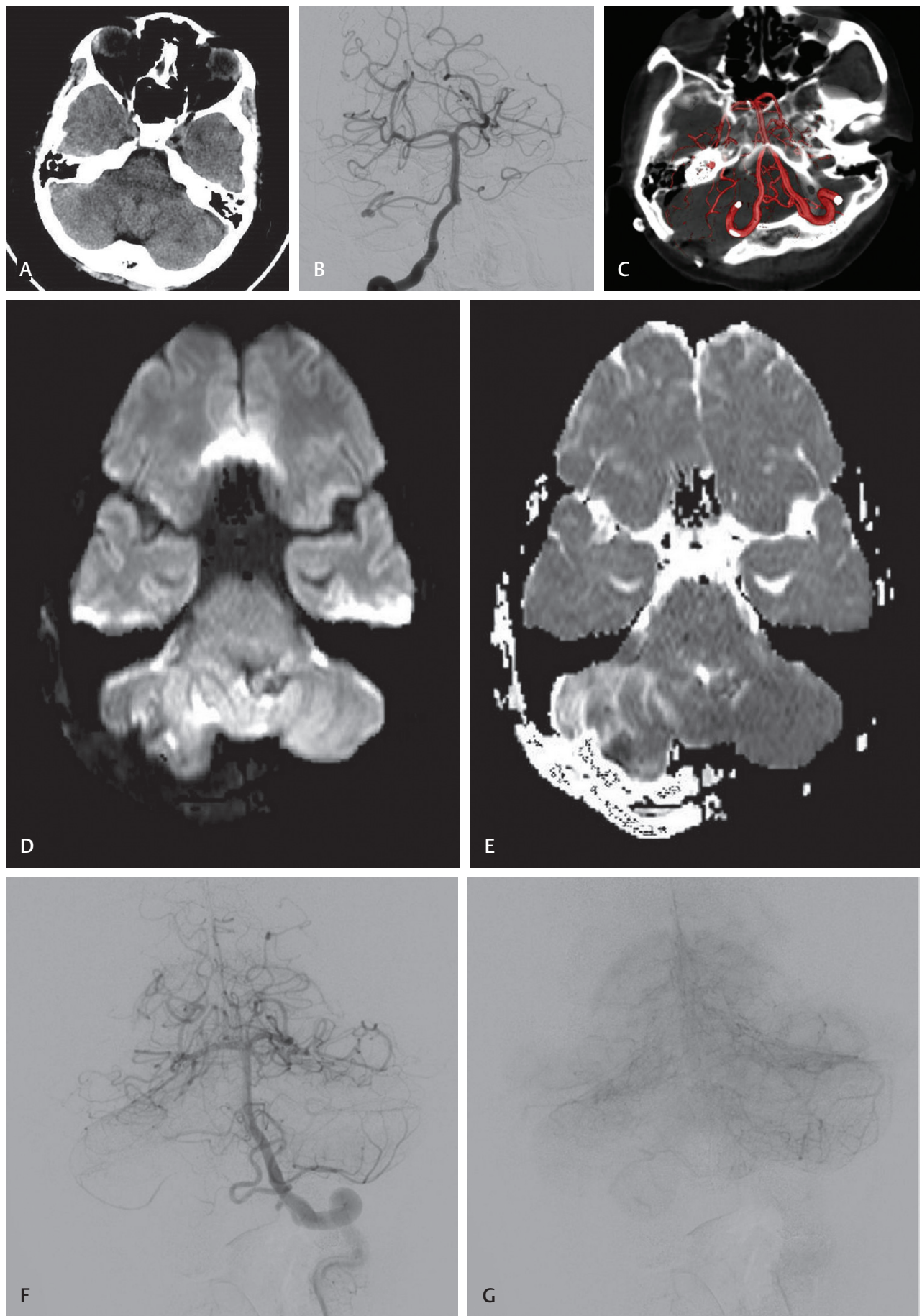

Fig. 1 DSA showing right AICA-PICA variant with distal aneurysm. (A) CT brain showing SAH. Right VA angiogram (B) \& 3D Angiogram overlapped to XPER CT (C) showing right AICA-PICA variant intrameatal aneurysm. Post surgical exploration MRI DWI (D) \& ADC (E) images. Post embolization left VA angiogram arterial phase $(\mathbf{F})$ and parenchymogram $(\mathbf{G})$ are shown.

\section{Discussion}

Distal AICA-PICA variant aneurysms are very rare with fewer than 10 cases reported till date..$^{1-8}$ Intrameatal location for AICA aneurysms is also uncommon. ${ }^{9}$ The AICA during its course has an abrupt turn at the internal auditory meatus and is in close relation to cranial nerve VII and VIII at that point. Common AICA-PICA trunk has similar course as that of AICA with the vessel dividing in rostral and caudal division. The caudal division reaches inferior surface of cerebellum and then takes over the territory of PICA. ${ }^{3}$ The vessel is in close proximity to cranial nerve VII and VIII in the loop at internal auditory meatus, and thus facial paresis or hearing impairment with or without tinnitus can be part of initial presentation of the aneurysm or complication of surgery. As intrameatal location is not a branching point, the possible etiology for aneurysm might be dissection or hemodynamic stress due to accentuated turn in the vessel.7 Surgical management of distal AICA or AICA-PICA variant aneurysms and intrameatal aneurysms has been proposed as first-line 

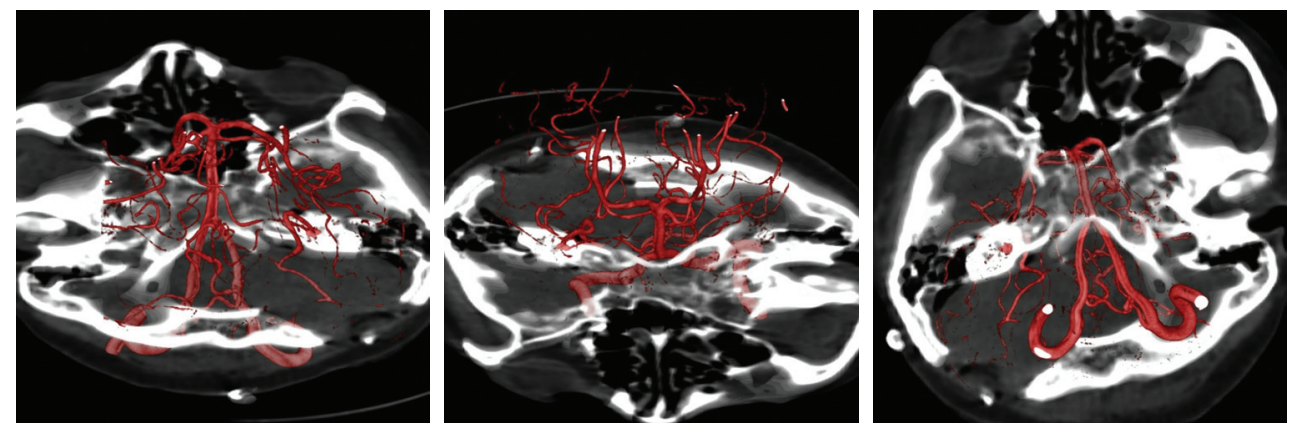

Fig. 2 Repeat DSA with 3D angiogram overlapped with Xper CT confirming an aneurysm in intrameatal location of right AICA-PICA common trunk.

management due to concerns regarding catheter navigation and possible adverse effects of parent vessel occlusion. ${ }^{7,10,11}$ An occipital to AICA bypass has also been proposed as part of management plan. ${ }^{1}$

Surgical management has high chances for postoperative morbidity due to deep location of aneurysm, proximity of important neurological structures to the aneurysm, and lack of expertise due to rarity of such aneurysms. Successful endovascular management of proximal AICA aneurysms has been reported previously. ${ }^{7}$ Only one AICA-PICA variant has been reported to be successfully managed endovascularly, but the patient had already sustained a cerebellar infarct. ${ }^{1}$ The outcome of this case suggests that endovascular management can help in successful management, with lesser complications, and it should be tried in distal AICA or AICA-PICA aneurysms and those in intrameatal locations. Preprocedure balloon test occlusion may help assess the possible postprocedure morbidity.

\section{Author Contributions}

Vikram Huded: Drafting the manuscript, study concept, supervision, and coordination.

Vikram Bohra: Drafting the manuscript, study design, literature search, interpretation of data, and acquisition of data. Romnesh DeSouza: Literature search, interpretation of data, and acquisition of data.

\section{Disclosures}

None.

\section{References}

1 Lasjaunias P, Berenstein A, ter Brugge KG. Clinical Vascular Anatomy and Variations. 2nd ed. Berlin, Heidelberg, Germany: Springer Berlin; 2001. Heidelberghttp://link.springer. com/10.1007/978-3-662-10172-8. Accessed January 4, 2016).
2 Baskaya MK, Coscarella E, Jea A, Morcos JJ. Aneurysm of the anterior inferior cerebellar artery-posterior inferior cerebellar artery variant: case report with anatomical description in the cadaver. Neurosurgery 2006;58(2):E388, discussion E388

3 Gopalakrishnan CV, Menon G, Nair S. Aneurysm of the anterior inferior cerebellar artery-posterior inferior cerebellar artery variant: two case reports and review of literature. $\mathrm{Br} J$ Neurosurg 2009;23(5):554-556

4 Suh SH, Kim DJ, Kim DI, et al. Management of anterior inferior cerebellar artery aneurysms: endovascular treatment and clinical outcome. AJNR Am J Neuroradiol 2011;32(1):159-164

5 Ooigawa H, Morikawa E, Ishihara S, et al. Partially thrombosed giant aneurysm arising from a distal anterior inferior cerebellar artery-posterior inferior cerebellar artery variant: a case report. Interdiscip Neurosurg 2015;2:123-125

6 Bambakidis NC, Manjila S, Dashti S, Tarr R, Megerian CA. Management of anterior inferior cerebellar artery aneurysms: an illustrative case and review of literature. Neurosurg Focus 2009;26(5):E6

7 Zotta DC, Stati G, De Paulis D, Galzio RJ. Intrameatal aneurysm of the anterior inferior cerebellar artery. J Clin Neurosci 2011;18(4):561-563

8 Ebara M, Tanaka T, Sawauchi S, Morooka S, Yuhki K, Abe T. [A ruptured aneurysm of the anterior and posterior inferior cerebellar artery: a case report] [in Japanese]. No Shinkei Geka 1999;27(11):1013-1017

9 Kim HC, Chang IB, Lee HK, Song JH. Ruptured total intrameatal anterior inferior cerebellar artery aneurysm. J Korean Neurosurg Soc 2015;58(2):141-143

10 Kojima A, Nakamura T, Takayama H, Harada S, Takamiya Y [A case of de novo aneurysm of the distal posterior inferior cerebellar artery with intraventricular hemorrhage] [in Japanese]. No Shinkei Geka 1996;24(5):469-473

$11 \mathrm{Gi} \mathrm{H}$, Inoha S, Uno J, et al. [Four cases of direct surgery for anterior inferior cerebellar artery aneurysms] [in Japanese]. No Shinkei Geka 2007;35(6):571-578 